\title{
Determinants of cough in young adults participating in the European Community Respiratory Health Survey
}

\author{
C. Janson*,\#, S. Chinn", D. Jarvis ${ }^{\#}$, P. Burney\#, on the behalf of the European Community \\ Respiratory Health Survey
}

Determinants of cough in young adults participating in the European Community Respiratory Health Survey. C. Janson, S. Chinn, D. Jarvis, P. Burney, on the behalf of the European Community Respiratory Health Survey. C ERS Journals Ltd 2001.

ABSTRACT: Cough is a common symptom that affects a large proportion of the general population. The aim of this investigation was to identify determinants of nocturnal, nonproductive and productive cough in population samples from different countries.

In a cross-sectional international population survey, 18,277 subjects (20-48 yrs) from 16 countries answered an interview-led questionnaire. Total and specific immunoglobulin-E was measured and spirometry was performed. Three types of cough were defined: nocturnal, nonproductive and productive cough. The relation of the independent variables to cough was estimated by means of logistic regression for each centre or country and combined across centre or country by random-effects meta-analysis.

The median prevalence of nocturnal, nonproductive and productive cough in the different centres was $30.7 \%, 10.2 \%$ and $10.2 \%$, respectively. Nocturnal and nonproductive cough were related to female sex (adjusted odds ratio $(\mathrm{OR})=\mathbf{2 . 0 8}$ and 1.27, respectively), while nocturnal and productive cough were related to rhinitis $(O R=1.46$ and 1.61, respectively). All three types of cough were related to asthma, tobacco smoking, environmental tobacco smoke and obesity.

Females are more likely to report nocturnal and nonproductive cough than males. Cough was related to treatable disorders, like asthma and rhinitis, as well as avoidable factors, such as tobacco smoking and environmental tobacco smoke.

Eur Respir J 2001; 18: 647-654.
*Dept of Medical Sciences, Respiratory Medicine and Allergology, Uppsala University, Uppsala, Sweden. ${ }^{\#}$ Dept of Public Health Sciences, King's College London, London, UK.

Correspondence: C. Janson, Dept of Respiratory Medicine, Akademiska sjukhuset, SE-751 85, Uppsala, Sweden. Fax: 46186112819

Keywords: Asthma

cough

environmental tobacco smoke

obesity

sex

smoking

Received: November 202000

Accepted after revision May 22001
Cough is a symptom that affects a large proportion of the general population [1, 2] and can cause a deterioration of an affected subject's quality of life [3]. Cough is a common symptom in various respiratory disorders, such as asthma, chronic bronchitis and bronchiectasis [4, 5]. Gastro-oesophageal reflux and postnasal secretion are other important disorders, where cough is common [4-6]. In previous population studies, the reported prevalence of long-term cough has varied from $11 \%$ in Sweden to $18 \%$ in the USA $[1,7]$.

Cough is provoked by physical or chemical stimulation of irritant receptors in the larynx, trachea or the bronchial tree. The mechanisms through which a disease causes cough are partly unknown but may be related to epithelial damage, increased mucosal permeability and release of neuropeptides [8]. Experimental studies have found that females have more sensitive cough reflexes than males [9, 10], and females are more likely to experience cough when treated with angiotensin converting enzyme blockers [11]. The reason for this sex difference remains to be explained.

In two previous investigations based on the Swedish part of the European Community Respiratory Health Survey (ECRHS), a higher prevalence of nocturnal and nonproductive cough was found in females than in males $[12,13]$. This sex difference was not explained by differences in possible confounding variables, such as smoking, psychological factors or asthma [13]. Independent predictors of productive cough in that investigation were smoking, asthma, rhinitis and gastro-oesophageal reflux.

The aim of this investigation was to identify

The following grants helped to fund the local studies. Australia: Allen and Hanbury's, Australia. Belgium: Belgian Science Policy Office, National Fund for Scientific Research. Estonia: The Estonian Scientific Foundation (grant 1088), GlaxoWellcome. France: Ministere de la Santé, Glaxo France, Insitut Pneumologique d'Aquitaine, Contrat de Plan Etat-Région Languedoc-Rousillon, CNMATS, CNMRT (90MR/ 10, 91AF/6), Ministre delegué de la santé, RNSP. Germany: GSF, and the Bundesminister für Forschung und Technologie, Bonn. Italy: Ministero dell'Universita e della Ricerca Scientifica e Tecnologica, CNR, Regione Veneto grant RSF n. 381/05.93. New Zealand: Asthma Foundation of New Zealand, Lotteries Grant Board, Health Research Council of New Zealand. Norway: Norwegian Research Council project no. 101422/310. Spain: Ministero Sanidad y Consumo FIS grants no. 91/0016060/00E-05E, no. 92/0319, no. 93/0393, Hospital General de Albacete, Hospital General Juan Ramón Jiménez, Consejeria de Sanidad Principado de Asturias. Sweden: The Swedish Heart Lung Foundation, the Swedish Medical Research Council, the Swedish Association against Asthma and Allergy. Switzerland: Swiss National Science Foundation grant 4026-28099. UK: National Asthma Campaign, British Lung Foundation, Dept of Health, South Thames Regional Health Authority. USA: United States Department of Health, Education and Welfare Public Health Service Grant no. 2 S07 RR05521-28. 
determinants of nocturnal, nonproductive and productive cough in the ECRHS.

\section{Population and methods}

\section{Population}

The methodology for the ECRHS has been fully described elsewhere [14]. Participating centres selected an area defined by pre-existing administrative boundaries with a population of $\geqslant 150,000$. When possible, an up-to-date sampling frame was used to randomly select $\geqslant 1,500$ males and 1,500 females, aged 20 44 yrs. In stage I, subjects were sent the ECRHS screening questionnaire, which asked about symptoms suggestive of asthma, the use of medication for asthma, and the presence of hay fever and nasal allergies. In stage II, a smaller, random sample of subjects who had completed the screening questionnaire was invited to attend for a more detailed interview-led questionnaire, blood tests for the measurement of total and specific immunoglobulin-E (IgE), spirometry and methacholine challenge. In this analysis, all 36 centres with both questionnaire and $\operatorname{IgE}$ data were included.

\section{Questionnaire}

The interview-led questionnaire contained, among other items, questions on respiratory symptoms, selfreported asthma and allergic disorders, date of birth, sex, smoking habits and environmental exposure.

Nocturnal cough. Nocturnal cough was defined as answering "yes" to the question: "Have you been woken by an attack of coughing at any time in the last 12 months?"

Nonproductive cough. Nonproductive cough was defined as: 1) answering "yes" to at least one of the following questions: "Do you usually cough first thing in the morning in the winter?" and "Do you usually cough during the day or at night in the winter?"; and 2) a negative answer to both of the following questions: "Do you usually bring up any phlegm from your chest during the day or at night in the winter?" and "Do you usually bring up any phlegm from your chest first thing in the morning in the winter?" [13].

Productive cough. Productive cough was defined as: 1) answering "yes" to at least one of the questions on winter cough; and 2) answering "yes" to at least one of the questions on phlegm production [13].

Asthma. Asthma was defined as answering "yes" to the question: "Have you ever had asthma?"

Allergic rhinitis. Allergic rhinitis was defined as answering "yes" to the question: "Do you have hay fever or any other kind of allergic rhinitis?"

Height and weight. Height and weight were measured prior to lung function measurement. Body mass index
(BMI) was calculated using the formula: (weight in $\mathrm{kg}$ )/ (height in $\mathrm{m})^{2}$.

Smoking history. The participants were asked whether they had smoked at least one cigarette per day or one cigar a week for $1 \mathrm{yr}$ or $360 \mathrm{~g}$ tobacco in a lifetime. The subjects were categorized into three groups: neversmokers, exsmokers and current smokers. Current smokers were categorized in two groups: moderate smokers $(<20 \mathrm{~g}$ tobacco per day) and heavy smokers $(\geqslant 20 \mathrm{~g}$ tobacco per day) [15]. Current tobacco smoking was also expressed as the estimated average amount of tobacco smoked in $\mathrm{g} \cdot \mathrm{day}^{-1}$. In this analysis, one cigarette was equivalent to $1 \mathrm{~g}$ tobacco.

Environmental tobacco smoke. Environmental tobacco smoke (ETS) exposure was defined as the estimated average numbers of hours of exposure to other people's tobacco smoking.

Seasonal variation. The cough questions were related to cough during winter, while the study was performed during all seasons. In order to investigate whether the time of the examination influenced the results, the time of season for the investigation was used as the confounding variable comparing winter-spring to summer-autumn. Winter-spring was defined as December-May in the Northern Hemisphere and June-November in Australia and New Zealand.

\section{Lung function and allergy testing}

Forced expiratory volume in one second (FEV1) was, in this analysis, expressed as a percentage of the predicted value [16]. Methacholine challenge was carried out using a dosimeter (Mefar, Brescia, Italy). The level of bronchial responsiveness was expressed using the ECRHS slope [17].

Total and specific IgE was measured using the Pharmacia CAP System (Pharamcia Diagnostics, Uppsala, Sweden). In all centres, specific IgE was measured against Dermatophagoides pteronyssinus, timothy grass, cat and Cladosporium herbarum. Detection of specific IgE $\left(>0.35 \mathrm{kU} \cdot \mathrm{L}^{-1}\right)$ was used as the definition of sensitization.

\section{Statistical analysis}

The Chi-squared test was used in the univariate analysis. Logistic regression was used when calculating odds ratios (ORs) for the influence of independent variables on cough. The adjusted ORs were estimated separately in each centre. Average effect estimates were derived and potential heterogeneity between centres examined using standard methods for random-effects meta-analysis [18]. When analysing determinants of nonproductive and productive cough, there were insufficient data in some centres to estimate the OR while adjusting for confounders. In these analyses, ORs were therefore estimated separately by country, adjusting for centre within each country. The 
results of the adjusted estimates are presented as ORs (95\% confidence interval).

\section{Results}

This analysis includes data from 36 centres in 16 countries. No data on bronchial responsiveness were available for two of the centres (Cardiff, UK and Tartu, Estonia). Altogether, 8,746 males and 9,531 females (mean age 34, range 20-48 yrs) were included. The prevalence of nocturnal, nonproductive and productive cough is presented in table 1 . There was a large variation in the prevalence of nocturnal and productive cough both between countries and between centres within individual countries (figs. 1 and 2). Of the 18,277 subjects included, spirometry was performed in 15,547, $\operatorname{IgE}$ measurements in 14,015 and methacholine challenge in 12,942 . The prevalence of current smoking varied from $21.3 \%$ in Portland, USA to $56.9 \%$ in Oviedo, Spain. The proportion of subjects who reported that they were regularly exposed to other people's tobacco smoke for $\geqslant 1 \mathrm{~h}$ per day varied from $21.7 \%$ in Umeå, Sweden to $81.1 \%$ in Galdakao, Spain. In the whole sample, $26.0 \%$ reported that they were exposed to ETS for $\geqslant 4 \mathrm{~h}$ per day.

The possible influence of age, sex, asthma, rhinitis, smoking history and ETS on cough was first studied with univariate analysis within each centre. Exsmoking was not significantly associated with an increased prevalence of any type of cough in any centre, while the prevalence of all types of cough was higher in heavy smokers than in moderate current smokers in most centres. This suggested a dose-related association between tobacco smoking and cough. Tobacco smoking was, therefore, expressed as g tobacco per day in all multivariable analyses. The prevalence of nocturnal, nonproductive and productive cough in relation to smoking history for all subjects is presented in table 2 . The prevalence of asthma among subjects with nocturnal cough in the whole sample was $12.7 \%$, and the corresponding prevalence for

Table 1. - Prevalence of nocturnal, nonproductive and productive cough

\begin{tabular}{|c|c|c|c|c|c|c|}
\hline Country & Centre & $\begin{array}{c}\text { Subjects } \\
\mathrm{n}\end{array}$ & $\begin{array}{l}\text { Nocturnal } \\
\text { cough }\end{array}$ & $\begin{array}{l}\text { Nocturnal } \\
\text { cough only }\end{array}$ & $\begin{array}{l}\text { Nonproductive } \\
\text { cough }\end{array}$ & $\begin{array}{l}\text { Productive } \\
\text { cough }\end{array}$ \\
\hline Iceland & Reykjavik & 558 & 21.3 & 14.1 & 10.2 & 10.0 \\
\hline Norway & Bergen & 834 & 27.8 & 17.3 & 10.1 & 10.0 \\
\hline \multirow[t]{3}{*}{ Sweden } & Göteborg & 682 & 40.9 & 28.4 & 8.2 & 9.4 \\
\hline & Umeå & 552 & 29.7 & 19.0 & 5.5 & 10.5 \\
\hline & Uppsala & 622 & 38.1 & 26.7 & 11.2 & 8.7 \\
\hline Estonia & Tartu & 431 & 35.5 & 19.1 & 12.3 & 16.5 \\
\hline \multirow[t]{3}{*}{ The Netherlands } & $\begin{array}{l}\text { Bergen-op- } \\
\text { Zoom }\end{array}$ & 451 & 26.8 & 18.0 & 11.5 & 7.5 \\
\hline & Geleen & 413 & 34.9 & 26.4 & 10.9 & 5.6 \\
\hline & Groningen & 380 & 27.6 & 19.0 & 8.4 & 6.8 \\
\hline \multirow[t]{2}{*}{ Belgium } & Antwerp City & 562 & 34.2 & 18.7 & 15.0 & 14.2 \\
\hline & South Antwerp & 557 & 23.2 & 12.0 & 12.4 & 9.9 \\
\hline \multirow[t]{2}{*}{ Germany } & Erfurt & 731 & 11.9 & 5.3 & 13.1 & 6.8 \\
\hline & Hamburg & 1252 & 26.9 & 16.0 & 14.1 & 7.9 \\
\hline Switzerland & Basel & 839 & 30.4 & 22.8 & 9.8 & 7.2 \\
\hline \multirow[t]{4}{*}{ France } & Bordeaux & 544 & 32.7 & 18.8 & 16.0 & 11.6 \\
\hline & Grenoble & 473 & 28.1 & 20.7 & 7.4 & 7.6 \\
\hline & Montpellier & 456 & 32.5 & 20.6 & 8.6 & 9.9 \\
\hline & Paris & 652 & 33.0 & 22.7 & 11.4 & 9.0 \\
\hline \multirow[t]{4}{*}{ UK } & Cambridge & 277 & 34.7 & 26.0 & 8.3 & 3.6 \\
\hline & Cardiff & 377 & 34.5 & 16.2 & 8.5 & 22.3 \\
\hline & Ipswich & 418 & 20.6 & 13.2 & 6.9 & 7.7 \\
\hline & Norwich & 472 & 34.8 & 20.1 & 13.1 & 12.1 \\
\hline Ireland & Dublin & 436 & 30.7 & 13.0 & 9.2 & 27.4 \\
\hline \multirow[t]{3}{*}{ Italy } & Pavia & 309 & 23.6 & 14.2 & 6.5 & 11.3 \\
\hline & Turin & 244 & 32.8 & 21.7 & 6.6 & 13.5 \\
\hline & Verona & 340 & 23.8 & 17.9 & 7.1 & 5.9 \\
\hline \multirow{5}{*}{ Spain } & Albacete & 435 & 30.6 & 14.9 & 12.2 & 17.2 \\
\hline & Barcelona & 393 & 26.7 & 21.6 & 5.8 & 5.1 \\
\hline & Galdakao & 486 & 29.2 & 18.5 & 9.0 & 10.7 \\
\hline & Huelva & 271 & 30.3 & 13.6 & 11.8 & 17.7 \\
\hline & Oviedo & 355 & 31.8 & 17.2 & 10.4 & 16.1 \\
\hline \multirow{3}{*}{ New Zealand } & Christchurch & 456 & 34.4 & 19.5 & 13.6 & 11.6 \\
\hline & Hawkes Bay & 316 & 41.8 & 27.5 & 9.2 & 11.1 \\
\hline & Wellington & 480 & 40.3 & 25.3 & 10.2 & 12.5 \\
\hline Australia & Melbourne & 669 & 36.3 & 26.5 & 7.3 & 8.5 \\
\hline USA & Portland & 556 & 34.2 & 18.2 & 11.0 & 17.3 \\
\hline Median & & & 31.2 & 18.9 & 10.2 & 10.2 \\
\hline
\end{tabular}

Data are presented as percentages unless otherwise stated. ${ }^{\#}$ : Nocturnal cough, but no reported productive or nonproductive cough. 
a)

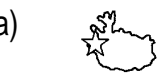

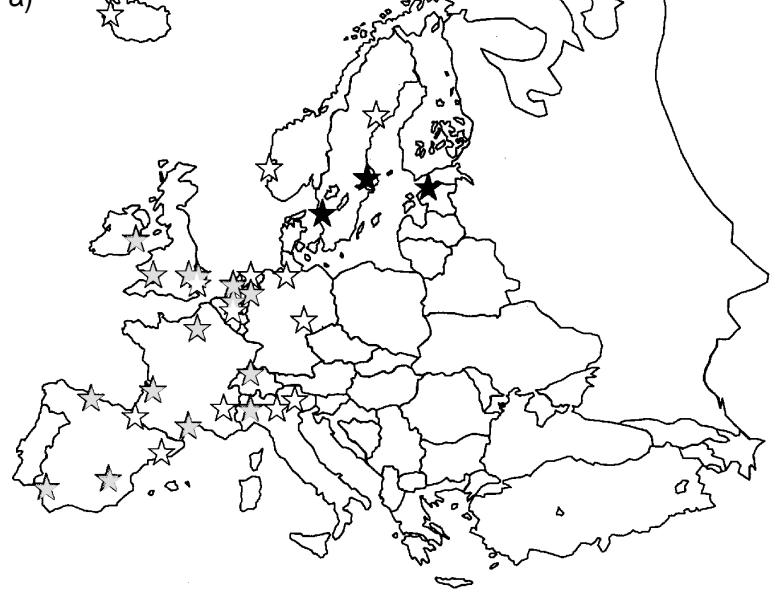

b)
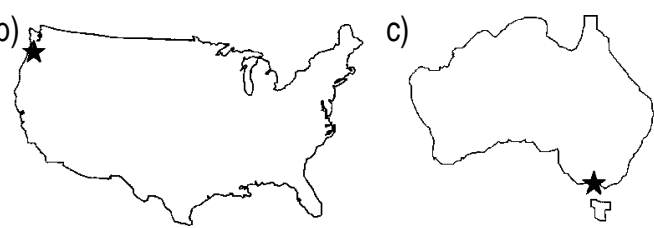

Fig. 1.- The geographical variation (a) Europe, b) USA, and c) Australasia) in the prevalence ( $\%$ ) of nocturnal cough (having been woken by an attack of coughing at any time in the last 12 months). Open stars: $<30 \%$; shaded stars: $30-35 \%$; solid stars: $>35 \%$.

nonproductive and productive cough was $12.0 \%$ and $17.0 \%$, respectively.

Multivariable analysis showed that nocturnal cough was related to female sex, increasing BMI, asthma,

a)
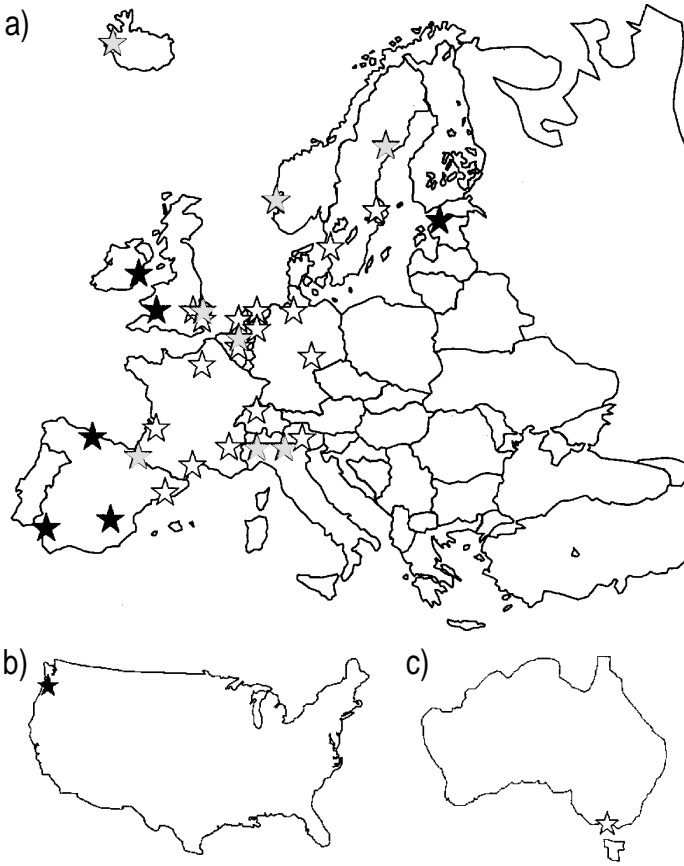

Fig. 2. - The geographical variation (a) Europe, b) USA, and c) Australasia) in the prevalence (\%) of productive cough (usually having cough and bringing up phlegm in the winter). Open stars: $<10 \%$; shaded stars: $10-15 \%$; solid stars: $>15 \%$.
Table 2.-Prevalence of nocturnal, nonproductive and productive cough in relation to smoking history

Smoking history

Never- Exsmoker Moderate Heavy smoker smoker smoker

\begin{tabular}{lrrrr}
\hline Nocturnal cough & 27.0 & 27.4 & 33.5 & 39.6 \\
Nonproductive cough & 8.2 & 6.7 & 12.4 & 18.7 \\
Productive cough & 6.1 & 6.7 & 12.3 & 26.8 \\
\hline
\end{tabular}

Data are presented as percentages. Moderate smoker: those smoking $<20 \mathrm{~g}$ tobacco per day; Heavy smoker: those smoking $\geqslant 20 \mathrm{~g}$ tobacco per day.

Table 3. - Odds ratio (OR) (95\% confidence interval (CI)) of nocturnal cough by age, sex, body mass index (BMI), asthma, rhinitis, smoking and environmental tobacco smoke (ETS)

\begin{tabular}{lcc}
\hline & OR $(95 \% \mathrm{CI})$ & $\begin{array}{c}\text { Heterogeneity }^{\#} \\
\text { p-value }\end{array}$ \\
\hline Age 10 yr increase & $0.99(0.93-1.05)$ & 0.46 \\
Females & $2.08(1.89-2.29)$ & 0.18 \\
BMI $5 \mathrm{~kg} \cdot \mathrm{m}^{-2}$ & $1.16(1.10-1.22)$ & 0.53 \\
Ever-asthma & $1.75(1.50-2.05)$ & 0.34 \\
Rhinitis & $1.46(1.32-1.62)$ & 0.85 \\
Smoking 10 g. day $^{-1}$ & $1.34(1.22-1.48)$ & 0.03 \\
ETS 4 h.day & $1.12(1.08-1.17)$ & 0.60 \\
\hline
\end{tabular}

\#: test for heterogeneity between centres. ORs were adjusted for sensitization to mite, cat, timothy grass and Cladosporium herbarum, total immunoglobulin-E, forced expiratory volume in one second and other independent variables in the table, and they were combined across centres by randomeffects meta-analysis.

rhinitis, smoking and ETS (table 3). In the analysis, adjustment was made for sensitization to mite, cat, timothy grass and C. herbarum, total IgE, and FEV1. There was a significant heterogeneity between centres in the relationship between smoking and nocturnal cough (fig. 3). A significant positive association between tobacco smoking and nocturnal cough was found in 19 of the centres. No centre showed a significant negative association between tobacco smoking and nocturnal cough. The prevalence of nonproductive or productive cough among subjects with nocturnal cough was $37.3 \%$. When nocturnal cough was defined as having nocturnal cough but not productive or nonproductive cough, no significant association was found between smoking and nocturnal cough $(1.00(0.90-1.10))$. All other associations remained significant.

When comparing the risk pattern for nonproductive and productive cough, female sex was related to nonproductive but not to productive cough. Increasing age was associated with a decreased risk for nonproductive cough, while there was no significant relation between age and productive cough. Productive cough was more strongly related to asthma and rhinitis than nonproductive cough, as shown by the greater ORs (table 4). A positive association between BMI was found both for nonproductive and productive cough. There was a significant heterogeneity 


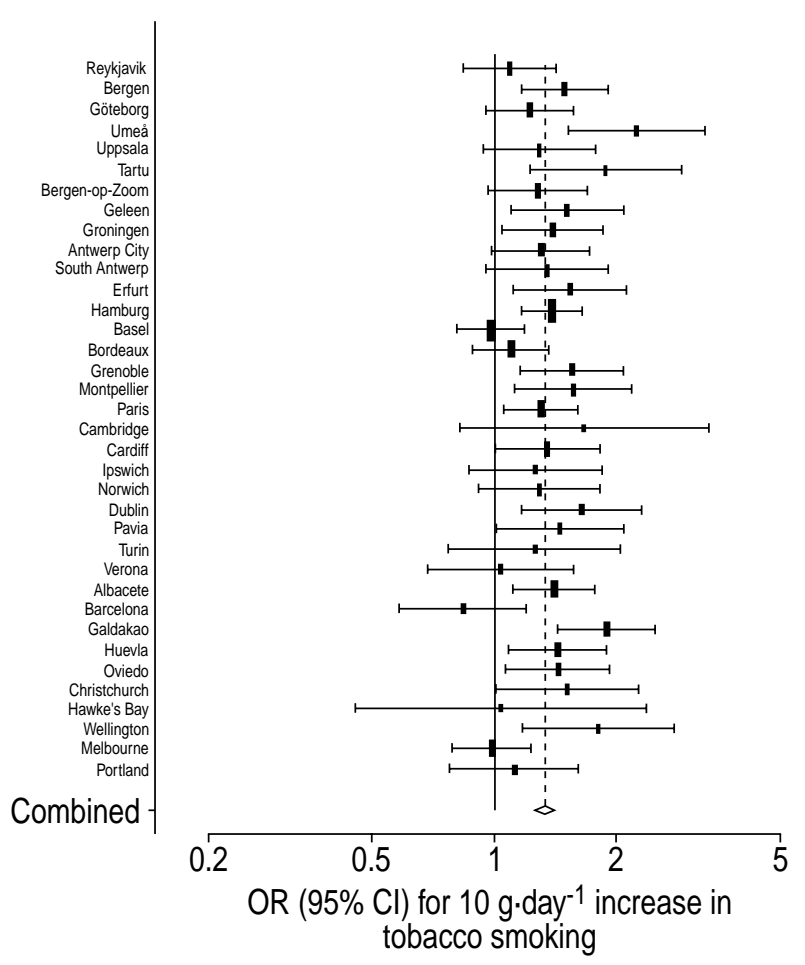

Fig. 3. - Adjusted odds ratios (ORs) and 95\% confidence interval (CI) of nocturnal cough with increase in tobacco smoking expressed as $10 \mathrm{~g}$ tobacco per day (adjusted within centre for age, body mass index, asthma, rhinitis, environmental tobacco smoke, sensitization to mite, cat, timothy grass and Cladosporium herbarum, total immunoglobulin-E and forced expiratory volume in one second) with combined OR (diamond indicates $95 \% \mathrm{CI}$ ) from the model with centre as the random effect. The size of each square is proportional to the sample size. A log scale is displayed on the $\mathrm{x}$-axis.

between countries in the relationship between smoking and nonproductive cough (fig. 4). A significant positive association between tobacco smoking and nonproductive cough was found in nine of the 16 countries, but a significant negative association between tobacco smoking and nocturnal cough was not found in any country. There was also betweencountry heterogeneity in the association between ETS and productive cough (fig. 5). A significant positive association between ETS and productive cough was

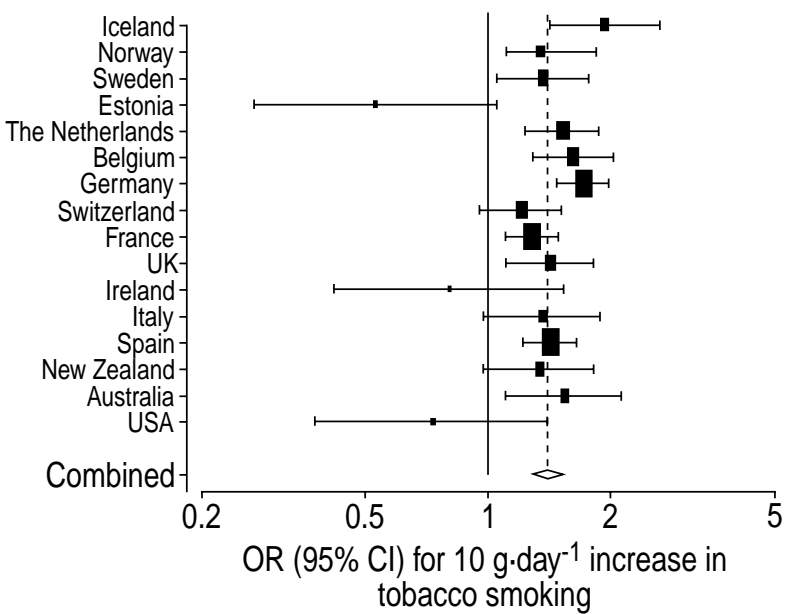

Fig. 4. - Adjusted odds ratios (ORs) and 95\% confidence interval (CI) of nonproductive cough with increase in tobacco smoking expressed in the unit $10 \mathrm{~g}$ tobacco per day (adjusted within countries for age, body mass index, asthma, rhinitis, environmental tobacco smoke, sensitization to mite, cat, timothy grass and Cladosporium herbarum, total immunoglobulin-E, forced expiratory volume in one second and centre) with combined OR (diamond indicates $95 \% \mathrm{CI}$ ) from the model with country as the random effect. The size of each square is proportional to the sample size. A $\log$ scale is displayed on the $\mathrm{x}$-axis.

found in Sweden, France, the UK and the USA. When widening the definition of productive cough by including all subjects that reported that they usually bring up phlegm during the winter months, regardless of whether they reported cough or not, the prevalence of productive cough increased to $17.3 \%$. With this wider definition, a negative association was found between productive cough and female sex $(0.80$ $(0.72-0.89))$. All the other associations with productive cough remained significant.

When the data with bronchial responsiveness and season as additional confounding variables were analysed, the association between BMI and nonproductive cough was no longer significant (1.05 (0.95-1.16)). Apart from this, all other associations remained significant. No significant interaction was found in the association between ETS and nocturnal, nonproductive or productive cough in nonsmokers or smokers. The possibility of a sex difference between

Table 4.-Odds ratio (OR) (95\% confidence interval $(\mathrm{Cl})$ ) of nonproductive and productive habitual cough by age, sex, body mass index (BMI), asthma, rhinitis, smoking and environmental tobacco smoke (ETS)

\begin{tabular}{|c|c|c|c|c|}
\hline & \multicolumn{2}{|c|}{ Nonproductive cough } & \multicolumn{2}{|c|}{ Productive cough } \\
\hline & OR $(95 \% \mathrm{CI})$ & Heterogeneity $^{\#}$ p-value & OR $(95 \% \mathrm{CI})$ & Heterogeneity $^{\#}$ p-value \\
\hline Age $10 \mathrm{yr}$ increase & $0.83(0.76-0.91)$ & 0.50 & $0.91(0.82-1.01)$ & 0.17 \\
\hline Females & $1.27(1.12-1.45)$ & 0.33 & $0.96(0.85-1.09)$ & 0.75 \\
\hline $\mathrm{BMI} 5 \mathrm{~kg} \cdot \mathrm{m}^{-2}$ & $1.10(1.01-1.22)$ & 0.47 & $1.12(1.04-1.22)$ & 0.96 \\
\hline Ever-asthma & $1.47(1.17-1.85)$ & 0.26 & $2.57(2.13-3.11)$ & 0.97 \\
\hline Rhinitis & $1.15(0.98-1.35)$ & 0.33 & $1.61(1.37-1.90)$ & 0.29 \\
\hline Smoking $10 \mathrm{~g} \cdot \mathrm{day}^{-1}$ & $1.34(1.22-1.48)$ & 0.01 & $1.97(1.79-2.16)$ & 0.08 \\
\hline ETS $4 \mathrm{~h}$ exposed & $1.13(1.07-1.22)$ & 0.52 & $1.13(1.04-1.26)$ & 0.04 \\
\hline
\end{tabular}

${ }^{\#}$ : test for heterogeneity between countries. ORs were adjusted for sensitization to mite, cat, timothy grass and Cladosporium herbarum, total immunoglobulin-E, forced expiratory volume in one second, centre and other independent variables in the table, and they were combined across countries by random-effects meta-analysis. 


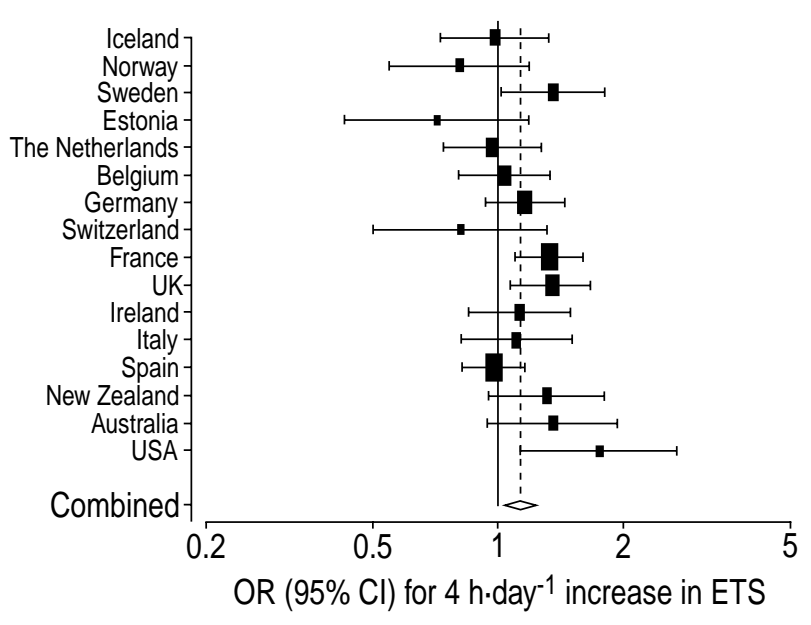

Fig. 5.-Adjusted odds ratios (ORs) and 95\% confidence interval (CI) of productive cough with increase in environmental tobacco smoke (ETS) exposure expressed in the unit $4 \mathrm{~h} \cdot \mathrm{day}^{-1}$ (adjusted within countries for age, body mass index, asthma, rhinitis, ETS, sensitization to mite, cat, timothy grass and Cladosporium herbarum, total immunoglobulin-E, forced expiratory volume in one second and centre) with combined OR (diamond indicates $95 \%$ CI) from the model with country as the random effect. The size of each square is proportional to the sample size. A log scale is displayed on the $\mathrm{x}$-axis.

the association of cough with BMI was also investigated by test of interaction. No sex differences in the association between BMI and any type of cough were found.

\section{Discussion}

The main results of this investigation are that nocturnal and nonproductive cough are related to female sex, while all three types of cough are related to asthma, tobacco smoking, exposure to ETS and obesity. The study also confirms that cough is a common symptom. About one-third of the subjects in this sample reported that they had been woken by an attack of cough in the last 12 months, while 20\% reported that they usually had nonproductive or productive cough during the winter months.

There was no clear pattern in the geographical variation of the various types of cough. This could to some extent reflect linguistic and cultural differences, but it should be noted that there were also large variations in prevalence between centres within countries. It is also important to notice that in most analyses there was no significant difference between countries in the association between the different determinants and the three types of cough. The prevalence of nocturnal cough was higher than nonproductive and productive cough. The reason for these differences in prevalence was that nocturnal cough was defined as any episode during the last 12 months, while the definitions for the other types of cough related to more long-term problems.

In many ways, this investigation confirms the results of a previous analysis of data from one of the Swedish centres [13], but the much larger population sample enabled the authors to study associations that it was not possible to investigate within the local centre analysis. As in the authors' previous investigation, it was found that nocturnal and nonproductive cough were associated with female sex. Nonproductive cough is a common side-effect of treatment with angiotensin-converting enzyme blockers. This side-effect has been reported to be more common in females than in males [11]. This analysis is in accordance with studies that have found that females have more sensitive cough receptors than males [9, 10]. The biological explanation for this is unknown. Sex hormones have been shown to have an effect on airway smooth muscle tone and bronchial responsiveness $[19,20]$. It is therefore possible that the sex difference in cough sensitivity is related to hormonal factors. The association between female sex and nonproductive cough could alternatively be related to under-reporting of productive cough in females. However, such a sex-related recall bias could not explain all of the sex association with cough in the present investigation, as female sex remained a significant independent determinant of cough when combining nonproductive and productive cough as one overall category $(1.15(1.03-1.27))$.

Nonproductive cough was found to be negatively related to age. The same pattern was found in the previous investigation based on one centre, but there the relation was statistically nonsignificant [13]. The present results correspond with the results of some of the previous analyses of the ECRHS data, where a negative association between age and respiratory symptoms has been found $[12,21]$. As this is a crosssectional study, it is not possible to state whether this indicates that nonproductive cough decreases with age or that the present results indicate a cohort effect, suggesting that the prevalence of nonproductive cough is increasing in the population. No corresponding relation was found between age and nocturnal or productive cough.

In the present study, increasing BMI was associated with increased risk of all three types of cough. This corresponds with the results of studies that have found a positive association between asthma and obesity [22, 23]. In most studies, the association between obesity and asthma has only been found in females. In the present investigation, it was not possible to detect any sex difference in the relationship between BMI and cough. A possible explanation for the relationship between obesity and cough is that increased BMI is associated with increased risk of gastro-oesophageal reflux, which is a well-known cause of chronic cough [4-6]. Unfortunately, it was not possible to analyse a direct relationship between gastro-oesophageal reflux and cough, as this information was not collected in the questionnaire. Respiratory infection and sinus disease are other important determinants of cough that were not covered in the present study.

Asthma is a well-recognized cause of cough [4, 5]. A strong positive association between all types of cough and asthma was found in this study. In most centres, however, only $10-20 \%$ of subjects that reported cough had self-reported asthma. Cough may sometimes be the only manifestation of asthma [24], and it is likely that some subjects with cough, but no reported asthma, have "cough variant asthma". The association 
between rhinitis and cough is also well known. Rhinitis is often associated with postnasal drip, which is one of the most common reasons for longterm cough $[4,5]$. Longitudinal studies also indicate that rhinitis is often a precursor to asthma $[25,26]$. It is, therefore, possible that the association between rhinitis and cough in the present investigation may to some extent be related to undetected asthma.

Current smoking was associated with all types of cough. The risk of cough increased with the amount of tobacco smoked. This association is well known $[1,2]$ and clinically important, as smoking is an avoidable cause of coughing. The present investigation also suggests that the exposure to ETS is another avoidable cause of cough. ETS is associated with respiratory symptoms and lower lung function in children $[27,28]$, but in some studies, it has also been found to increase the risk and severity of asthma and respiratory symptoms in adults [29-31]. The present results suggest that cough may be another negative consequence of ETS. Somewhat surprisingly, the association between ETS and cough did not differ between nonsmokers and smokers. In the present analysis, pipe and cigar smokers were included, but as they are a minority, the increased OR per $10 \mathrm{~g}$ of tobacco is approximately equivalent to the increased risk per 10 cigarettes per day.

Nocturnal cough is important, as it may potentially affect quality of sleep and thereby negatively affect daytime alertness. This has, however, not been studied extensively and a study on children suggests that the sleep disturbing effect of nocturnal cough is rather small [32]. The risk factor pattern of nocturnal cough showed many similarities to that of nonproductive cough, with a strong association with female sex, and, compared to productive cough, less association with active smoking. Nocturnal cough was, however, related more to asthma and rhinitis than to nonproductive cough.

The choice of the independent variables in the present analysis was based on the results of a previous investigation from one centre in the ECRHS [13] and on the findings of several studies on patients with long-term cough [3-5]. In the analysis, the authors adjusted for IgE-sensitization and lung function. Bronchial responsiveness has, like cough, been associated with female sex and smoking in previous ECRHS analyses [15, 33]. Adding bronchial responsiveness as an independent variable did not, however, affect the sex associations with nocturnal and nonproductive cough or the association between smoking and all three types of cough. The questions on nonproductive and productive cough were related to cough during the winter months. It was therefore possible that subjects answering the questions during winter or spring may have given a more accurate account than subjects answering the questions during summer or autumn. Adjusting for time of questioning did not, however, significantly alter the present results.

The authors conclude that cough is a common symptom in all centres of the European Community Respiratory Health Survey and that females are more likely to report nocturnal and nonproductive cough than males. Cough was related to treatable disorders like asthma and rhinitis, as well as to avoidable factors, such as tobacco smoking and environmental tobacco smoke.

Acknowledgements. The coordination of this work was supported by the European Commission and the authors are grateful to $\mathrm{C}$. Baya and M. Hallen for their help during the study and to K. Vuylsteek and the members of the COMAC for their support.

Principal participants of the ECRHS study. Coordinating Centre (London): P. Burney, S. Chinn, C. Luczynska, D. Jarvis, E. Lai. Australia: M. Abramson, J. Kutín Melbourne); Belgium: P. Vermeire, F. van Bastelaer (Antwerp South, Antwerp Central); France: J. Bousquet (Montpellier), F. Neukirch, R. Liard (Paris), I. Pin, C. Pison (Grenoble), A. Taytard (Bordeaux); Estonia: R. Jogi (Tartu); Germany: H. Magnussen, D. Nowak (Hamburg); H.E. Wichmann, J. Heinrich (Erfurt); Iceland: T. Gislason, D. Gislason (Reykjavik); Ireland: J. Prichard, S. Allwright, D. MacLeod (Dublin); Italy: M. Bugiani, C. Bucca, C. Romano (Turin), R. de Marco, V. Lo Cascio, C. Campello (Verona), A. Marinoni, I. Cerveri, L. Casali (Pavia); the Netherlands: B. Rijcken, A. Kremer (Groningen, Bergen-op-Zoom, Geleen); New Zealand: J. Crane, $\mathrm{S}$. Lewis (Wellington, Christchurch, Hawkes Bay); Norway: A. Gulsvik, E. Omenaas, C. Svanes (Bergen); Spain: J. Antó, J. Sunyer, J. Soriano, A. Tobías, J. Roca, M. Kogevinas (Barcelona), N. Muniozguren, J. Ramos González, A. Capelastegui (Galdakao), J. Martinez-Moratalla, E. Almar (Albacete), J. Maldonado, A. Pereira, J. Sánchez (Huelva), F. Payo, I. Huerta (Oviedo); Sweden: G. Boman, C. Janson, E. Björnsson (Uppsala), L. Rosenhall, E. Norrman B. Lundbäck (Umeå), N. Lindholm, P. Plaschke (Goteborg); Switzerland: U. Ackermann-Liebrich, N. Künzli, A. Perruchoud (Basel); UK: M. Burr, J. Layzqll (Caerphilly), R. Hall (Ipswich), B. Harrison (Norwich), J. Stark (Cambridge); USA: S. Buist, W. Vollmer, M. Osborne (Portland).

\section{References}

1. Barbee RA, Halonen M, Kaltenborn WT, Burrows B. A longitudinal study of respiratory symptoms in a community population sample. Correlations with smoking, allergen skin-test reactivity, and serum IgE. Chest 1991; 99: 20-26.

2. Cullinan P. Persistent cough and sputum prevalence and clinical characteristics in south east England. Respir Med 1992; 86: 143-149.

3. French CL, Irwine RS, Curley FJ, Krikorian CJ. Impact of chronic cough on quality of life. Arch Intern Med 1998; 158: 1657-1661.

4. Irwin RS, Curley FJ, French CL. Chronic cough: The spectrum and frequency of causes, key components of the diagnostic evaluation, and outcome of special therapy. Am Rev Respir Dis 1990; 141: 640-647.

5. Smyrnios NA, Irwin RS, Curley FJ, French CL. From a prospective study of chronic cough: diagnosis and therapeutic aspects. Arch Intern Med 1998; 158: 1222 1228.

6. Irwin RS, French CL, Curley FJ, Zawacki JK, Bennett FM. Chronic cough due to gastroesophageal 
reflux. Clinical, diagnostic, and pathogenetic aspects. Chest 1993; 104: 1511-1517.

7. Lundbäck B, Nyström L, Rosenhall L, Stjernberg N. Obstructive lung disease in northern Sweden: respiratory symptoms assessed in a postal survey. Eur Respir $J$ 1991; 4: 257-266.

8. Forsythe P, Mcgarey PA, Heaney LG, Macmahon J, Ennis M. Sensory neuropeptides induce histamine release from bronchoalveolar lavage cells in both nonasthmatic coughers and cough variant asthmatics. Clin Exp Allergy 2000; 30: 225-232.

9. Fujimura M, Kasahara K, Kamio Y, Naruse M, Hashimoto T, Matsuda T. Female gender as a determinant of cough threshold to inhaled capsaicin. Eur Respir J 1996; 9: 1624-1626.

10. Diepinigaitis PV, Rauf K. The influence of gender on cough reflex sensitivity. Chest 1998; 113: 1319-1321.

11. Os I, Bratland B, Dahlöf B, Gisholt K, Syvertsen JO, Tretli S. Female preponderance for lisinopril-induced cough in hypertension. Am J Hypertens 1994; 7: 1012 1015.

12. Björnsson E, Plaschke $\mathrm{P}$, Norrman E, et al. A population-based study of symptoms related to asthma and chronic bronchitis in three areas of Sweden. Eur Respir J 1994; 7: 2146-2153.

13. Ludviksdottir D, Björnsson E, Janson C, Boman G. Habitual coughing; association to asthma, anxiety and gastroesophageal reflux. Chest 1996; 109: 1262-1268.

14. Burney PGJ, Luczynska C, Chinn S, Jarvis D. The European Community Respiratory Health Survey. Eur Respir J 1994; 7: 954-960.

15. Leynaert B, Bousquet J, Henry C, Liard R, Neukirch $\mathrm{F}$. Is bronchial hyperresponsiveness more frequent in women than in men? A population-based study. Am J Respir Crit Care Med 1997; 156: 1413-1420.

16. European Community for Coal Steel. Standardization of lung function tests. Clin Respir Phys 1983; 19: Suppl. 5, 22-27.

17. Chinn S, Burney P, Jarvis D, Luczynska C. European Community Respiratory Health Survey. Variation in bronchial responsiveness in the European Community Respiratory Health Survey. Eur Respir J 1997; 10: 2495-2501.

18. Der Simonian R, Liard N. Meta-analysis in clinical trials. Control Clin Trials 1986; 7: 117-188.

19. Foster PS, Goldie RG, Paterson JW. Effect of steroids on $\beta$-adrenoreceptor-mediated relaxation of pig bronchus. Br J Pharmacol 1983; 78: 441-445.

20. Tan KS, McFarlane LC, Lipworth BJ. Modulation of airway reactivity and peak flow variability in asthmatics receiving the oral contraceptive pill. $\mathrm{Am}$ J Respir Crit Care Med 1997; 155: 1273-1277.

21. Neukirch F, Pin I, Knani J, et al. Prevalence of asthma and asthma-like symptoms in three French cities. Respir Med 1995; 89: 685-692.

22. Huang SL, Shiao GM, Chou P. Association between body mass index and allergy in teenage girls in Taiwan. Clin Exp Allergy 1999; 29: 323-329.

23. Shaheen SO, Sterne JAC, Montgomery SM, Azima H. Birth weight, body mass index and asthma in young adults. Thorax 1999; 54: 396-402.

24. Gibson PG, Hargreave FE, Girgis-Garbado A, Morris M, Denburg JA, Dollowich J. Chronic cough with eosinophil bronchitis: examination for variable airflow obstruction and responsiveness to corticosteroid. Clin Exp Allergy 1995; 25: 127-132.

25. Settipane RJ, Hagy GW, Settipane GA. Long term risk factors for developing asthma and allergic rhinitis: a 23 year follow-up study of college students. Allergy Proc 1994; 15: 21-25.

26. Plaschke $\mathrm{P}$, Janson C, Norrman E, Björnsson E, Ellbjär S, Järvholm B. Onset and remission of allergic rhinitis and asthma and the relationship with atopic sensitization and smoking. Am J Respir Crit Care Med 2000; 162: 920-924.

27. Cunningham J, O'Connors GT, Dockery DW, Speizer FE. Environmental tobacco smoke, wheezing and asthma in children in 24 communities. Am J Respir Crit Care Med 1996; 153: 218-224.

28. Cook DG, Strachan DP, Carey IM. Health effects of passive smoking 9. Parental smoking and spirometric indices in children. Thorax 1998; 53: 884-893.

29. Coultas DB. Health effects of passive smoking 8 . Passive smoking and risk of adult asthma and COPD. Thorax 1998; 53: 381-387.

30. Leuenberger P, Schwartz J, Ackermann-Liebrich U, et al. Passive smoking exposure in adults and chronic respiratory symptoms. Am J Respir Crit Care Med 1994; 150: 1222-1228.

31. Blanc PD, Ellbjär S, Janson C, et al. Asthma related work disability in Sweden: the impact of workplace exposures. Am J Respir Crit Care Med 1999; 160: 2028-2033.

32. Fuller P, Picciotto A, Davies M, McKenzie SA. Cough and sleep in inner-city children. Eur Respir $J$ 1998; 12: 426-431.

33. Norrman E, Plaschke P, Björnsson E, et al. Prevalence of bronchial hyperresponsiveness in the southern, middle and northern parts of Sweden. Respir Med 1998; 92: 480-487. 